\title{
Anaerobic Utilization of Uric Acid by Some Group D Streptococci
}

\author{
By G. C. MEAD \\ A.R.C. Food Research Institute, Colney Lane, Norwich NOR $70 F$
}

(Received 17 December 1973)

\section{INTRODUCTION}

Among the Lancefield Group D streptococci, the enterococcus group as defined by Sherman (1937) comprises two main physiological types which relate either to Streptococcus faecalis or S. faecium (Deibel, 1964a). Deibel, Lake \& Niven (1963) stated that a third species, $S$. durans (Sherman \& Wing, 1937), should be considered as a variety of $S$. faecium. This classification is supported by the results of various physiological and serological tests and was confirmed in a numerical taxonomic study (Jones, Sackin \& Sneath, 1972). The present paper describes a further differential characteristic: the ability of $S$. faecalis but not $S$. faecium or $S$. durans to utilize uric acid.

\section{METHODS}

Organisms. The strains used were: Streptococcus durans (NCIB662, NCIB8587, NCIB8782, NCTC8307, and two additional strains isolated from pigs); S. faecalis var. faecalis (NCIB775, seven additional strains isolated from chickens, and two from humans); S. faecalis var. liquefaciens ( 2 strains isolated from chickens, five from humans and one from a sheep); $S$. faecalis var. zymogenes (eight strains isolated from chickens and three from humans); S. faecium (26 strains isolated from chickens, ten from humans and two from pigs).

Approximately two-thirds of the test organisms originated from the laboratory collection of Dr E. M. Barnes; the remainder were freshly isolated from either chicken caecal samples or samples of human faeces and identified as described by Sharpe, Fryer \& Smith (1966). Cultures were maintained at ambient temperature in cooked meat medium. Test media were inoculated from overnight aerobic cultures in Difco heart infusion or brain-heart infusion medium (see below) and incubated at $37^{\circ} \mathrm{C}$.

Breakdown of uric acid. Initially cultures were streaked on double-layered agar plates incorporating a I $\%(\mathrm{w} / \mathrm{v})$ suspension of uric acid (Sigma) in the upper layer and $0.1 \%$ in the lower layer (Schefferle, 1965; Barnes, Mead, Barnum \& Harry, 1972). Positive strains produced zones of clearing in the suspended uric acid within 10 days at $37{ }^{\circ} \mathrm{C}$. However, the following method generally gave more rapid positive results and required less uric acid in the test medium. Each strain was streaked on two agar slopes of the following basal medium, one containing $0.2 \%(w / v)$ of uric acid and one without: Difco Tryptone, I \%; Difco yeast extract, $0.5 \%$; glucose, $0.05 \%$; phenol red, $0.0012 \%$; New Zealand agar $\mathrm{I} \cdot 2 \%$; pH 7.2. The slopes, comprising $10 \mathrm{ml}$ of medium in $19 \times 150 \mathrm{~mm}$ test tubes plugged with cotton wool, were incubated under $\mathrm{H}_{2}$ in an anaerobic jar.

After incubation for up to 7 days, the two cultures of each strain were compared and any difference in colour was noted. Fermentation of the small amount of glucose in the basal medium produced an acid (yellow) reaction. This was rapidly followed by the development of alkaline conditions during the breakdown of uric acid and a change in the colour of the indicator to cherry red. 
Table 1. Growth of representative strains of Streptococcus faecalis in a complex medium containing uric acid or glucose as the main energy source

Growth was measured at $24 \mathrm{~h}$. Basal medium was supplemented with either uric acid or glucose (Io $\mu \mathrm{mol} / \mathrm{ml}$ ).

Incubation
Strain $\quad \begin{aligned} & \text { Basal } \\ & \text { conditions }\end{aligned}$

Stimulation of growth. Tests for growth stimulation by uric acid or glucose used the complex liquid basal medium and methods of Deibel (1964 b). The medium was freshly prepared and, where required, anaerobic conditions were obtained with an anaerobic jar. Growth was measured with an EEL nephelometer calibrated with an arbitrary standard opacity tube. A reading of 40 corresponded to approximately $0.9 \mathrm{mg}$ dry wt $/ \mathrm{ml}$; the relation between nephelometer readings and dry weight was linear between readings of Io and 45 . In each case the inoculum was $0.05 \mathrm{ml}$ of an overnight aerobic culture in Difco brain-heart infusion medium washed twice in $0.025 \mathrm{M}$-phosphate buffer and resuspended in fresh buffer solution. No attempt was made to exclude oxygen during the preparation of the inoculum.

\section{RESULTS AND DISCUSSION}

After anaerobic growth, 36 out of 39 strains of Streptococcus faecalis (all varieties) decomposed uric acid within seven days, and only NCIB775 (var. faecalis) and single strains of var. faecalis from a chicken and var. liquefaciens of human origin were negative. All 38 strains of $S$. faecium and all six strains of $S$. durans also gave negative results. When incubated in air a few strains of $S$. faecalis were weakly positive but the remainder of the test organisms were negative.

Thirteen strains of Streptococcus faecalis were positive anaerobically within 24 to $36 \mathrm{~h}$ and finally produced an intense cherry-red colour in the uric acid medium. Eight strains produced a much weaker but still clearly discernible reaction after 7 days under the same conditions, while the behaviour of the remaining strains fell between these extremes.

Highly active strains were found among both human and chicken isolates, although such strains might be expected to occur more abundantly in the bird, where uric acid is the main nitrogenous excretory product. The possibility that uric acid may be utilized anaerobically by various types of bacteria in the chicken caecum has been discussed by Barnes et al. (1972).

Tests were made with one uric acid-decomposing strain of each Streptococcus faecalis variant for the ability to produce ammonia from adenine, guanine, xanthine, cytosine, thymine and uracil; all strains were negative whether incubated in air or under hydrogen.

Table I shows the growth of one highly active uric acid-decomposing strain of Streptococcus faecalis var. zymogenes (EB/F/30/27 isolated from a chicken) and one moderately active strain of $S$. faecalis var. liquefaciens $(\mathrm{GB} / \mathrm{I} \mathrm{I} 2$, of human origin) in the complex basal medium of Deibel $(1964 b)$, both with and without the addition of Io $\mu$ mol uric acid or glucose $/ \mathrm{ml}$. Uric acid stimulated the growth of both strains during anaerobic but not aerobic 
incubation for $24 \mathrm{~h}$, and comparable growth was obtained on both uric acid and glucose in each case under the conditions used. Single strains of $S$. durans and $S$. faecium were unable to utilize uric acid in the same basal medium under either aerobic or anaerobic conditions.

In preliminary experiments with washed suspensions of Streptococcus faecalis EB/F/30/27, the products of uric acid utilization were ammonia, carbon dioxide and acetic acid.

The author is indebted to Dr E. M. Barnes for providing strains and to Miss J. E. Maskell for technical assistance.

\section{REFERENCES}

Barnes, E. M., Mead, G. C., Barnum, D. A. \& Harry, E. G. (1972). The intestinal flora of the chicken in the period 2 to 6 weeks of age, with particular reference to the anaerobic bacteria. British Poultry Science r3, 3 I I-326.

Deibel, R. H. (1964a). The group D streptococci. Bacteriological Reviews 28, 330-366.

DeIBEL, R. H. (1964b). Utilization of arginine as an energy source for the growth of Streptococcus faecalis. Journal of Bacteriology 87, 988-992.

Deibel, R. H., LAKe, D. E. \& Niven, C. F. (1963). Physiology of the enterococci as related to their taxonomy. Journal of Bacteriology 86, 1275-1282.

Jones, D., Sackin, M. J. \& SNEATH, P. H. A. (I972). A numerical taxonomic study of streptococci of serological group D. Journal of General Microbiology 72, 439-450.

SCHEFFERLE, H. E. (1965). The decomposition of uric acid in built up poultry litter. Journal of Applied Bacteriology 28, 412-420.

ShARPE, M. E., FRYER, T. F. \& SMITH, D. G. (I966). Identification of the lactic acid bacteria. In Identification Methods for Microbiologists, Part A. Society for Applied Bacteriology: Technical Series No. I, pp. 65-79. Edited by B. M. Gibbs and F. A. Skinner. London: Academic Press.

Sherman, J. M. (1937). The streptococci. Bacteriological Reviews 1, 3-97.

Sherman, J. M. \& WING, H. U. (1937). Streptococcus durans. Journal of Dairy Science 20, I65-I67. 